\title{
Cochlear implantation: a biomechanical prosthesis for hearing loss
}

\author{
Robert Yawn, Jacob B. Hunter, Alex D. Sweeney, and Marc L. Bennett*
}

\author{
Address: The Otology Group, Department of Otolaryngology-Head and Neck Surgery, The Bill Wilkerson Center for Otolaryngology \& \\ Communication Sciences 7209 Medical Center East, South Tower 1215 21st Avenue South, Nashville, TN 37232, USA \\ * Corresponding author: Marc L. Bennett (marc.bennett@vanderbilt.edu) \\ Fl000Prime Reports 2015, 7:45 (doi:10.12703/P7-45) \\ All F1000Prime Reports articles are distributed under the terms of the Creative Commons Attribution-Non Commercial License \\ (http://creativecommons.org/licenses/by-nc/3.0/legalcode), which permits non-commercial use, distribution, and reproduction in any medium, \\ provided the original work is properly cited. \\ The electronic version of this article is the complete one and can be found at: http://fl000.com/prime/reports/m/7/45
}

\begin{abstract}
Cochlear implants are a medical prosthesis used to treat sensorineural deafness, and one of the greatest advances in modern medicine. The following article is an overview of cochlear implant technology. The history of cochlear implantation and the development of modern implant technology will be discussed, as well as current surgical techniques. Research regarding expansion of candidacy, hearing preservation cochlear implantation, and implantation for unilateral deafness are described. Lastly, innovative technology is discussed, including the hybrid cochlear implant and the totally implantable cochlear implant.
\end{abstract}

\section{Introduction}

Cochlear implants are one of the most profound advances in modern medicine. As a therapeutic option for sensorineural hearing loss, they are fundamentally distinct from hearing aids, and work by converting sound into an electrical stimulus that bypasses the hair cells of the human cochlea and directly stimulates the cochlear nerve. As of December 2012, over 300,000 people worldwide have received cochlear implants, with approximately 60,000 adults and 40,000 children being implanted in the US [1].

As mentioned, cochlear implants are different from hearing aids in that they do not simply amplify sound. They bypass the ear's normal sound conducting mechanism, stimulating the acoustic nerve directly. An external microphone captures sound and relays it to a processor, which then sends it to a transmitter that communicates wirelessly with a receiver under the skin. The receiver then converts the sound into electrical impulses that are carried by an electrode array that is surgically placed adjacent to auditory nerve fibers within the cochlea. The signal is transmitted within the central auditory system, which generally remains intact in deaf patients, to the auditory cortex, allowing patients to hear. We present a summary review of cochlear implants, including their historical underpinnings, current indications, procedural description, including complications, as well as current topics of discussion within the field of cochlear implantation.

\section{History of cochlear implantation}

Electrical stimulation of the auditory system is not a new concept. In 1748, Benjamin Wilson used a Leyden jar to stimulate hearing in a deaf woman. Alessandro Volta, an Italian physicist, undertook similar experiments in the 1800 s, but stopped because of the discomfort from the electrical stimulation [2]. In 1957, two French physicianscientists, Djourno and Eyries, implanted a device that directly stimulated the auditory nerve; the patient had sound awareness for several weeks until the device stopped working. Shortly thereafter, in 1961, Dr. William House of Los Angeles placed the first cochlear implant in a patient [3].

Initially, cochlear implants were single channel electrodes with minimal capabilities. Graeme Clark of Australia and Ingeborg and Erwin Hochmair of Austria pioneered the development of multichannel implants in the late 1970s $[4,5]$. Additionally, Michael Merzenich was influential in understanding the effects of electrical stimulation of the cochlear nerve and in developing multichannel implants at the University of California, San Francisco [6,7]. Using a multichannel electrode, stimulation at multiple locations 
along the cochlea became possible, allowing for a more complex and realistic signal to be created. In the US, Blake Wilson further improved the quality of speech recognition with cochlear implants by programming electrodes to minimize cross-stimulation and electrode interference within the cochlea [8].

Cochlear implants were officially approved by the United States Food and Drug Administration (FDA) in 1984 [9]. The first marketed cochlear implant in the US was the single-channel implant created through a partnership between Dr. House and 3M. Soon thereafter, Nucleus Limited partnered with the Australian Department of Productivity and the University of Melbourne to produce and market one of the first commercially available multichannel implants. Currently, five companies manufacture cochlear implants: Advanced Bionics, Cochlear, MED-EL, Neurelec of France, and Nurotron out of China, the first three of which are currently available in the US.

Early on in the development and advancement of cochlear implantation, advocates and opponents of the technology were vocal with their opposing viewpoints. Supporters championed the possibility of auditory rehabilitation in patients who previously would have had no access to hearing or who would have been limited to poorly performing hearing aids. Opponents regarded the new technology with hostility and skepticism, especially regarding the proposed use in children who were born deaf [2].

\section{Implant candidacy and evaluation}

Cochlear implant candidacy is assessed through a comprehensive audiologic and medical workup. Patients are considered to be conventional cochlear implant candidates if they have bilateral moderate-to-profound sensorineural hearing loss and receive little to no benefit from hearing aids. However, recently the criteria for implant candidacy has expanded, including FDA approval in children as young as one year of age, as well as patients who may have residual low-frequency hearing [10]. In addition to preoperative auditory testing, imaging is obtained, such as a computed tomography (CT) scan of the temporal bone or magnetic resonance imaging (MRI) of the brain to define the anatomy of the temporal bone and to rule out retrocochlear causes of hearing loss, specifically abnormalities of the cochlear nerve that may preclude cochlear implantation [8]. Once the patient is cleared for surgery, pneumococcal vaccines are administered for meningitis prophylaxis per FDA guidelines.

\section{Surgical technique}

The procedure is regularly performed under general anesthesia, with facial nerve monitoring. A post-auricular incision is made, followed by dissection of soft tissue to expose the mastoid, as well as establishing a subperiosteal pocket for the implant magnet to rest in. A cortical mastoidectomy is performed, identifying key temporal bone landmarks, including the incus, the lateral semicircular canal, the tegmen tympani, and the sigmoid sinus. The facial recess is opened, the boundaries of which are the facial nerve, chorda tympani, and a shelf of bone left superiorly to protect the incus, known as the incus buttress. The round window niche is identified through the recess.

After identifying the round window, several methods exist of accessing the scala tympani within the cochlea. Methods including drilling a separate hole, known as a cochleostomy, as well as removing any overhanging bone, and gently opening the round window with a straight pick. Lastly, an extended cochleostomy can be performed, simply drilling on the anterior limit of the round window. Once the cochlea is opened, the implant is slowly inserted into the cochlea.

An audiologist performs an integrity test at the conclusion of the procedure, ensuring proper functioning of the implant. The soft tissue and skin are then closed in layers. Some surgeons utilize plain radiographic analysis to ensure proper location of the implant. Once awake, the patients are usually discharged home the same day of surgery, and the implant is activated 2-4 weeks postoperatively.

\section{Complications}

Cochlear implantation is a safe surgical procedure performed around the world. Complications are generally classified as major complications, requiring additional surgery or cochlear explantation, and minor complications, requiring conservative medical management. Global complication rates are generally held to be approximately $16 \%$ [11]. Complication rates have decreased with smaller surgical incisions, increased experience, and improvements in device design, and are now generally held to be approximately $11.8 \%$ for minor complications and 3.2\% for major complications [12].

Major complications include infections, facial paralysis, and device failure. Infection rates range from $1-12 \%$ in the literature and the majority of these are skin infections or acute otitis media. Soft tissue infections and acute otitis media do not necessarily lead to implant removal, but do increase the risk of removal if the receiver stimulator appears to become infected. There is also a reported increased risk of bacterial meningitis after implantation that is held to be thirty-fold greater in implant recipients than in the general population, but thankfully these cases are quite sporadic with the advent of vaccination [13]. Currently the FDA recommends routine pneumococcal 
vaccination with the pneumococcal conjugate vaccine (PCV13) and the polysaccharide vaccine (PPSV23) prior to undergoing implantation [14]. The rate of transient facial nerve palsy is estimated to be approximately $0.7 \%$ [15]. This is possibly from heat transferred by the drill in opening the facial recess or performing a cochleostomy or extended round window approach. Another theory is reactivation of herpes simplex virus infection from the stress of surgery. In minor injuries, complete resolution of paresis is observed. Lastly, device failure requiring reimplantation is estimated to occur in $2.5-6 \%$ of cases $[11,12]$.

Postoperative vestibular symptoms are not uncommon. Severity varies, but it is believed that up to one-third of patients experience disequilibrium, vertigo, or vestibular weakness lasting more than 1 week postoperatively [16]. The majority of these cases resolve over weeks to months. Patients over 70 are most likely to have permanent vestibular weakness after cochlear implantation.

\section{Unilateral versus bilateral implantation}

Initially, cochlear implantation was only offered unilaterally. Surgeons began to question whether patients would perform better with unilateral or bilateral implants. Bilateral implantation patients demonstrated improved speech perception, and hearing in noise [11]. In addition, bilateral implant patients show significant improvement in sound localization, compared to their performance with a single implant [17].

Regarding surgical timing, bilateral implantation can be placed sequentially or simultaneously. In adults, studies have not shown a major difference in audiologic outcomes when timing between sequential implantation is minimized, and that the second ear matches the first ear's performance at 6 months [18]. However, children with simultaneous bilateral implantation demonstrated improved performance with speech recognition and language, when compared to children who were implanted sequentially [19].

While there are clear advantages to binaural stimulation, the cost-effectiveness of bilateral cochlear implantation is unclear. One study (out of Ontario, Canada) found the cost for unilateral implantation, including preoperative evaluation, surgery, and postoperative follow-up, was about $\$ 64,000$, with an incremental cost of the second implant being about $\$ 48,000$ (USD). The study found that cochlear implantation in adults is cost-effective, when compared to no implantation, though the benefit of sequential implantation is borderline, when compared to unilateral implantation [20]. Other studies have concluded that bilateral simultaneous pediatric implantation and unilateral adult cochlear implantation are cost-effective, but bilateral sequential pediatric implantation and bilateral (sequential or simultaneous) adult implantation are not cost-effective [21].

\section{Cochlear implantation for single-sided sensorineural hearing loss}

Implantation in the setting of single-sided deafness has recently emerged as an area of interest [22]. Historically, patients with single-sided deafness have the options of hearing aids, contralateral routing of signal (CROS) devices, or bone-anchored implants. But while CROS devices and bone-anchored implants route sound to the better hearing ear, cochlear implantation has the ability to restore sound to the deaf ear.

A particular challenge for patients with unilateral hearing loss is sound localization. Binaural stimulation and interaural time differences of stimulation allow for complex processing of sounds that facilitates localization. Studies in patients with unilateral hearing loss have demonstrated improvements in localization with cochlear implants as compared to bone anchored implants [23]. In addition to providing improved localization, a recent study analyzed the use of cochlear implantation for tinnitus suppression in patients with single-sided deafness [24]. Implantation led to increased speech perception in noise, improved sound localization, as well as decreased tinnitus. In some cases, complete tinnitus resolution is possible [25].

\section{Hearing preservation after cochlear implantation}

Another recent development is the emergence of evidence that acoustic hearing can be preserved despite implantation. Historically, the placement of an electrode into the fluid filled cochlea was believed to destroy the natural mechanism of hearing. However, it has been shown that hearing can be preserved in over half of patients receiving implants [26]. It is not uncommon for patients with severe-to-profound hearing loss to have some residual low-frequency hearing, and preservation of the natural hearing leads to improved speech understanding, sound localization, and hearing in complex listening environments [27]. Cochleostomy approach, electrode design, and steroids have been extensively studied for their effect on hearing preservation.

Several factors, including implant length and placement, are thought to influence hearing preservation during cochlear implantation. While the length of the electrode and its insertion depth can cause intracochlear trauma, studies have shown hearing preservation is possible in patients with full electrode insertion [28]. A recent study of 100 patients demonstrated that the best hearing 
preservation outcomes were seen when the electrode was located entirely within the scala tympani [24]. Thus, studies have investigated methods to maximize atraumatic scala tympani insertion. While some report that insertion of the electrode into the cochlea through a naturally existing pathway, such as the round window, is beneficial, others believe that making a separate opening in the cochlea, also known as a cochleostomy, is preferable. However, studies demonstrate there is no significant difference between surgical approaches regarding hearing outcomes $[29,30]$. However, a recent study showed that round window or extended round window approaches were more likely than cochleostomy approaches to place the electrode completely within the scala tympani, and thus increase hearing preservation [24].

Electrodes have also been designed to traverse the cochlea in various orientations, again to maximize placement within the scala tympani and minimizing trauma to the native cochlear anatomy. Perimodiolar implants are designed to hug the inside of the cochlea, while lateral wall electrodes are designed to adhere to the outside wall of the cochlea during insertion. Recently, studies have shown that lateral wall implants were more likely to remain within the scala tympani than perimodiolar implants [31].

Lastly, perioperative steroids have been shown to possibly contribute to the preservation of hearing. One study found that preoperative intratympanic steroid injections led to increased rates of hearing preservation, especially at low frequencies, and increased stability of hearing preservation over the first year after implantation [27]. In addition, steroid-eluting implants have been shown to improve hearing preservation rates up to 1 year from implantation [32].

\section{Other applications}

In hopes of preserving residual hearing, Gantz and colleagues at the University of Iowa developed a hybrid cochlear implant that is only $10 \mathrm{~mm}$ in length [33]. This allows for shallow insertion into the cochlea, stimulating the region responsible for high frequency hearing, and avoiding the region responsible for low frequency hearing, which can be intact in some patients undergoing cochlear implantation. Early studies showed hearing preservation and increased speech perception with implant use, with benefits in speech perception in excess of 2 years [29-30,32]. Patients with the hybrid implant also demonstrated improved appreciation of music, due to the benefit of combined acoustic and electrical stimulation [32]. In addition, implant performance of the hybrid was comparable to conventional cochlear implants [33]. However, with a progressive hearing loss, the replacement of the hybrid implant with a full-length implant has been shown to improve hearing and word recognition $[34,35]$, but adds significantly to cost.

Cochlear implantation has also been utilized in patients with profound sensorineural hearing loss and bilateral Meniere's disease. Meniere's disease consists of episodic attacks of hearing loss, tinnitus, and debilitating vertigo spells. In one study, patients that underwent cochlear implantation showed resolution of vertigo spells, improved tinnitus scores, and improved hearing performance [36]. However, their hearing outcomes are slightly worse than comparable patients implanted for other reasons [37].

\section{The totally implantable cochlear implant}

A current area of investigation is the development of a totally implantable device. Because implants require patients to wear an external microphone, processor, and transmitting coil to power the electrode, the implant use is limited to dry and relatively stable environments. The totally implantable cochlear implant is intended to bypass this challenge by having the entire system placed underneath the skin. In order for this concept to be feasible, the microphone must be sufficiently small and sensitive enough to detect sound through skin, while filtering internal noise from the body itself. In addition, the rechargeable battery must have a sufficiently long life (and be re-chargeable externally) and the entire system has to be small enough to be fully implanted. Three patients have been implanted with a totally implantable cochlear implant [38].

\section{Conclusion}

Cochlear implantation is one of the most significant advances in modern medicine. Patients also receive the benefits of relief from auditory isolation, gains in confidence, and increased ability to function in society. In addition to hearing improvement, patients note improved tinnitus and vertigo. Understanding that preservation of hearing is beneficial, soft-surgical techniques and pharmacologic interests are rapidly developing. However, cochlear implants do not restore all facets of hearing. As devices are developed with better processing, gains will be made in improving speech and noise and music appreciation, and the devices will continue to improve quality of life for patients with hearing loss for generations to come.

\section{Abbreviations}

CROS, contralateral routing of signal; FDA, Food and Drug Administration.

\section{Disclosures}

The authors declare that they have no disclosures. 


\section{References}

I. National Insitute on Deafness and Other Communication Disorders (NIDCD): Cochlear Implants. National Institute of Health (NIH), 2014. [http://www.nidcd.nih.gov/health/hearing/pages/coch.aspx].

2. Mudry A, Mills M: The early history of the cochlear implant: a retrospective. JAMA Otolaryngol Head Neck Surg 2013, I39:446-53.

3. O'Donoghue G: Cochlear implants-science, serendipity, and success. N Engl J Med 2013, 369: I 190-3.

4. Clark GM: Hearing due to electrical stimulation of the auditory system. Med J Aust 1969, I:I346-8.

5. Burian K, Hochmair E, Hochmair-Desoyer I, Lessel MR: Designing of and experience with multichannel cochlear implants. Acta Otolaryngol 1979, 87:190-5.

6. White MW, Merzenich MM, Gardi JN: Multichannel cochlear implants. Channel interactions and processor design. Arch Otolaryngol 1984, I 1 0:493-50I.

7. Schindler RA, Merzenich MM, White MW, Bjorkroth B: Multielectrode intracochlear implants. Nerve survival and stimulation patterns. Archives of otolaryngology 1977, 103:691-9.

8. Wilson BS, Finley CC, Lawson DT, Wolford RD, Eddington DK, Rabinowitz WM: Better speech recognition with cochlear implants. Nature 1991, 352:236-8.

9. Mangus B, Rivas A, Tsai BS, Haynes DS, Roland JT Jr: Surgical techniques in cochlear implants. Otolaryngol Clin North Am 2012, 45:69-80.

10. Klenzner T, Stecker M, Marangos N, Laszig R: [Extended indications for cochlear implantation. The Freiburg results in patients with residual hearing]. HNO 1999, 47:95-I00.

II. Venail F, Sicard M, Piron JP, Levi A, Artieres F, Uziel A, Mondain M: Reliability and complications of $\mathbf{5 0 0}$ consecutive cochlear implantations. Arch Otolaryngol Head Neck Surg 2008, I34:I276-8I.

\section{FlOOOPrime
RECOMMENDED}

12. Farinetti A, Ben Gharbia D, Mancini J, Roman S, Nicollas R, Triglia JM: Cochlear implant complications in $\mathbf{4 0 3}$ patients: comparative study of adults and children and review of the literature. Eur Ann Otorhinolaryngol Head Neck Dis 2014, I3 I:177-82.

\section{FlOOOPrime}

\section{RECOMMENDED}

13. Reefhuis J, Honein MA, Whitney CG, Chamany S, Mann EA, Biernath KR, Broder K, Manning S, Avashia S, Victor M, Costa P, Devine O, Graham A, Boyle C: Risk of bacterial meningitis in children with cochlear implants. N Engl J Med 2003, 349:435-45.

\section{FlOOOPrime
RECOMMENDED}

14. Kahue CN, Sweeney AD, Carlson ML, Haynes DS: Vaccination recommendations and risk of meningitis following cochlear implantation. Curr Opin Otalaryngol Head Neck Surg 2014, 22:359-66.

15. Fayad JN, Wanna GB, Micheletto JN, Parisie SC: Facial nerve paralysis following cochlear implant surgery. The Laryngoscope 2003, I I 3: 1344-6.

\section{FlOOOPrime}

\section{RECOMMENDED}

16. Enticott JC, Tari S, Koh SM, Dowell RC, O'Leary SJ: Cochlear implant and vestibular function. Otol Neurotol 2006, 27:824-30.

\section{FlOOOPrime}

\section{RECOMMENDED}

17. Dunn CC, Tyler RS, Witt S, Ji H, Gantz BJ: Sequential bilateral cochlear implantation: speech perception and localization pre- and post-second cochlear implantation. Am J Audiol 2012, 2I:181-9.

\section{FlOOOPrime \\ RECOMMENDED}

18. Reeder RM, Firszt JB, Holden LK, Strube MJ: A longitudinal study in adults with sequential bilateral cochlear implants: time course for individual ear and bilateral performance. J Speech Lang Hear Res 2014, 57:1 108-26.

\section{FIOOOPrime
RECOMMENDED}

19. Lammers MJ, Venekamp RP, Grolman W, van der Heijden GJ: Bilateral cochlear implantation in children and the impact of the inter-implant interval. Laryngoscope 2014, I24:993-9.

\section{FlOOOPrime}

RECOMMENDED

20. Chen JM, Amoodi H, Mittmann N: Cost-utility analysis of bilateral cochlear implantation in adults: a health economic assessment from the perspective of a publicly funded program. Laryngoscope 2014, I24:1452-8.

\section{FlOOOPrime}

\section{RECOMMENDED}

21. McKinnon BJ: Cost effectiveness of cochlear implants. Curr Opin Otolaryngol Head Neck Surg 2014, 22:344-8.

\section{FlOOOPrime}

RECOMMENDED

22. Kamal SM, Robinson AD, Diaz RC: Cochlear implantation in single-sided deafness for enhancement of sound localization and speech perception. Curr Opin Otolaryngol Head Neck Surg 2012, 20:393-7.

23. Nawaz S, McNeill C, Greenberg SL: Improving sound localization after cochlear implantation and auditory training for the management of single-sided deafness. Otol Neurotol 2014, 35:27 I-6.

\section{FlOOOPrime}

RECOMMENDED

24. Vlastarakos PV, Nazos K, Tavoulari EF, Nikolopoulos TP: Cochlear implantation for single-sided deafness: the outcomes. An evidence-based approach. Eur Arch Otorhinolaryngol 20 I 4, 27 I :2 I I 9-26.

\section{FlOOOPrime}

RECOMMENDED

25. Kim DK, Bae SC, Park KH, Jun BC, Lee DH, Yeo SW, Park SN: Tinnitus in patients with profound hearing loss and the effect of cochlear implantation. Eur Arch Otorhinolaryngol 20 I3, 270: I803-8.

\section{FlOOOPrime}

\section{RECOMMENDED}

26. Carlson ML, Driscoll CL, Gifford RH, Service GJ, Tombers NM, HughesBorst BJ, Neff BA, Beatty CW: Implications of minimizing trauma during conventional cochlear implantation. Otol Neurotol $201 \mathrm{I}$, 32:962-8.

\section{FlOOOPrime
RECOMMENDED}

27. Gifford RH, Dorman MF, Skarzynski H, Lorens A, Polak M, Driscoll CL, Roland $\mathrm{P}$, Buchman CA: Cochlear implantation with hearing preservation yields significant benefit for speech recognition in complex listening environments. Ear Hear 2013, 34:4I3-25.

\section{FlOOOPrime}

RECOMMENDED

28. Bruce IA, Bates JE, Melling C, Mawman D, Green KM: Hearing preservation via a cochleostomy approach and deep insertion of a standard length cochlear implant electrode. Otol Neurotol 201 I, 32:1444-7.

29. Adunka OF, Dillon MT, Adunka MC, King ER, Pillsbury HC, Buchman CA: Cochleostomy versus round window insertions: influence on functional outcomes in electric-acoustic stimulation of the auditory system. Otol Neurotol 2014, 35:6I3-8.

30. Havenith S, Lammers MJ, Tange RA, Trabalzini F, della Volpe A, van der Heijden GJ, Grolman W: Hearing preservation surgery: cochleostomy or round window approach? A systematic review. Otol Neurotol 2013, 34:667-74.

31. Wanna GB, Noble JH, Carlson ML, Gifford RH, Dietrich MS, Haynes DS, Dawant BM, Labadie RF: Impact of electrode design and surgical approach on scalar location and cochlear implant outcomes. Laryngoscope 2014, I 24(Suppl 6):SI-7. 
32. Douchement D, Terranti A, Lamblin J, Salleron J, Siepman F, Siepmann J, Vincent C: Dexamethasone eluting electrodes for cochlear implantation: Effect on residual hearing. Cochlear Implants Int 2014, [Epub ahead of print].

\section{FlOOOPrime}

33. Gantz BJ, Dunn CC, Walker EA, Kenworthy M, Van Voorst T, Tomblin B, Turner C: Bilateral cochlear implants in infants: a new approach-Nucleus Hybrid SI2 project. Otol Neurotol 2010, 31:1300-9.

\section{FlOOOPrime}

RECOMMENDED

34. Fitzgerald MB, Sagi $E$, Jackson $M$, Shapiro $W H$, Roland JT Jr, Waltzman SB, Svirsky MA: Reimplantation of hybrid cochlear implant users with a full-length electrode after loss of residual hearing. Otol Neurotol 2008, 29:168-73.

\section{FlOOOPrime \\ RECOMMENDED}

35. Carlson ML, Archibald DJ, Gifford RH, Driscoll CL, Beatty CW: Reimplantation with a conventional length electrode following residual hearing loss in four hybrid implant recipients. Cochlear Implants Int 2012, 13:148-55.

\section{FlOOOPrime}

RECOMMENDED

36. Hansen MR, Gantz BJ, Dunn C: Outcomes after cochlear implantation for patients with single-sided deafness, including those with recalcitrant Meniere's disease. Otol Neurotol 2013, 34: $1681-7$.

\section{FlOOOPrime}

RECOMMENDED

37. McRackan TR, Gifford RH, Kahue CN, Dwyer R, Labadie RF, Wanna GB, Haynes DS, Bennett ML: Cochlear implantation in Meniere's disease patients. Otol Neurotol 20I4, 35:42I-5.

38. Briggs RJ, Eder HC, Seligman PM, Cowan RS, Plant KL, Dalton J, Money DK, Patrick JF: Initial clinical experience with a totally implantable cochlear implant research device. Otol Neurotol 2008, 29: I| 4 -9.

\section{FloOOPrime}

\section{FeOPrime}

